\title{
Grammatical Attributes in the Language of Communication: Conceptualization of Time, Tense and Aspect in English
}

\author{
Dr Richard T. Torto \\ University of Cape Coast, Department of Communication Studies, Cape Coast, Ghana
}

\begin{abstract}
Time is a concept which is related to our perception of reality. A vast majority of languages have mechanisms which enable the speakers to express time. Many languages have grammatical means that make it possible for users to express the time when an action or event occurs. Among these languages, most of them also express time with a verb, and more specifically, with various verbal tenses. The verbal tense, a grammatical category which differs significantly from one language to another, may also be considered a grammatical component of time. Verbal tense can provide us with a particular kind of insight into our perception of chronological time which is expressed with and within the tense of the verb. Tense is concerned about how events are located, perceived and referred to along the past-present-future timeline. Aspect is about the manner in which a verbal action is experienced or regarded. In general linguistic approaches, tense and aspect are treated as complementary ways of encoding time. They relate the happening described by the verb to time in the past, present or future. However, tense differs from aspect in showing the time reference, while aspect shows how the action or state of the verb is envisaged or seen as happening or occurring. Time, tense and aspect are inter-related concepts; time is usually perceived in relation to tense and aspect. In the current paper, it is the author's conviction that knowledge in the distinction between the three concepts (time, tense, aspect) will enable English speakers to communicate better, grammatically.
\end{abstract}

Keywords: Time, Tense, Aspect, Grammar, English, Communication.

DOI: $10.7176 / \mathrm{NMMC} / 92-03$

Publication date:August $31^{\text {st }} 2020$

\section{Introduction}

Language is a system that governs human communication. Language serves as the vehicle for the expression of thoughts, concepts, perceptions, sentiments and values characteristic of human society. Language also represents a fundamental expression of social identity. It enables individuals to engage socially in a network of relationships and cultural experiences. Sapir (1921) defines language as a purely human and non-instinctive method of communicating ideas, emotions and desire by means of voluntarily produced symbols. This means language is associated with human beings and it is acquired for the purpose of communication. Krech, Crutchfield, and Ballachery (1962) also contribute views on the relationship between language and communication; according to them, language is the primary vehicle for the transmission of culture and human experiences. Language is therefore essentially a means of communication among members of a particular society. Being the most significant tool of communication, a language that has been developed by a speech community becomes a form of identity of the people. As a tool of communication, language also conveys traditions and values related to group identity (Sirbu, 2015).

In analyzing language, one observation that can be made is that our linguistic repertoire is quite limited; however, we generate limitless sentences when we communicate. Language is a system which includes the rules (grammar) that relate symbols and meaning. The meaning of each concept is permanently connected to a specific word. The relationship between the phonology and semantics of language is crucial to our ability to communicate. In processing language speakers share a common agreement on sound, rules of organization and meaning. For instance, speakers of English understand this interrogative string of words (what kind of weather are you experiencing in Accra?) as a question that does not elicit a yes/no response; it is a request for the receiver to demonstrate specific knowledge. The correct response to the interrogative sentence above is dependent on a combination of our understanding of sounds, the rules governing the organization of words into sentences and the meaning we attach to the words we use. Language and communication are interrelated concepts; knowledge about the processing of language goes a long way to enable us communicate better.

In the western tradition, basic conceptions of chronological time and verbal tense have been inherited from the ancient Greeks. According to Aristotle, a verb is a sound which conveys not only a particular meaning but also has a time reference (Quoted in Binnick, 1991). This definition of a verb has not changed significantly in current times. Indeed, a verb denotes or marks time since time dimension cannot be entirely ignored in any action or state. A verb is thus a part of speech which is closely linked with time. It is evident from ancient works that in the classical age the verb-time relation was considered a simple relation of a spectacular type (Lakoff \& Johnson, 1980). In this theory, verbal tense fully overlaps with chronological time and accurately expresses it by linguistic means. There is a complete equivalence between verbal tense and chronological time. What exists as chronological 
time in an extra-linguistic reality is a verbal tense in a linguistic reality.

Tenses, moods and aspects (TMA) belong to the things in one's native language that one tends to take for granted and often, they have only attracted the attention of grammarians who have had to explain the use of such categories in one language to speakers of another language in which the system is different. However, since the semantics of TMA categories is connected with concepts that are fundamental to human thinking, such as time, action, event, philosophers have often had occasion to reflect upon their use. In recent years, as the scope of general linguistic theory was widened, there has been an upsurge in studies of TMA systems, where the insights of earlier traditions have been exploited. Some languages have had their TMA systems described in hundreds of monographs and articles; yet, it is usually impossible to know to what extent the claims and the conceptual apparatus of these works can be extended to other languages. One constant source of confusion in the study of tense, mood and aspect categories is the complex interrelations between grammar and lexicon. The basic observation is that in addition to the fact that some aspectual notions are expressed by morphological means in some languages, it is also true for all languages that verbal lexemes differ in their aspectual potential. It is clear, for instance, that the verbs die and sleep are quite different as regards the contexts in which they occur naturally. To take a standard illustration of this fact, sleep but not die can be used together with a durational adverbial like for two hours. The obvious semantic correlate of this distributional fact is that die is normally used of punctual events, whereas sleep is used of prolonged states. Verb lexemes differ as to their Aktionsart or inherent aspectual meaning; In addition, some languages distinguish different morphological forms of the same lexemes, called aspect, according to the context in which the verbs are used.

According to Fairclough (1992), every instance of language use is a communicative event consisting of three dimensions: First, it is a text (speech, writing, visual image or a combination of these); second, it is a discursive practice which involves the production and consumption of texts; and third, it is a social practice. Fairclough's model also entails textual analysis which focuses on the formal features of language (lexicon, grammar, syntax, semantics and phonology) from which discourses are perceived linguistically. The current article focuses on the communicative functions of the three concepts in the English language, namely, time, tense and aspect through series of grammatical analysis and interpretations.

\section{Theoretical Perspectives}

The great expansion of linguistics as a discipline was associated with advances made in theories of grammar. The work of Chomsky (1965) in which he presented the Standard Theory of Generative Grammar generated new grammatical perspectives within linguistics. Today, there is perhaps a more even balance in the prominence of major areas of linguistic research, but theories of grammar are still regarded by many as the essential basis for any theory of language. When the term grammar is used in phrases such as case grammar or systemic grammar it is in a broad sense, referring to a theory of language. It is also commonly used in a more restricted sense, to refer to syntactic structure or the descriptions of the syntactic structure of a particular language. Sometimes these descriptions use the framework that has been developed as part of a theory of language, so that we may have, for example, a transformational grammar of English (Graddol, Cheshire \& Swam, 1987). Linguistic theory is concerned primarily with an ideal speaker-listener, in a completely homogeneous speech-community, in which speakers know their language perfectly and are unaffected by such grammatically irrelevant conditions as memory limitations, distractions, shifts of attention and interest and errors in applying their knowledge of the language in actual performance. Speakers of a language know the principles that govern the organization of words into longer sequences though they may not necessarily be consciously aware of their linguistic knowledge.

There are many distinct frameworks employed by linguists to analyze syntactic structure. Since the knowledge that people have about their language is very complex, it is difficult to devise a single framework that can satisfactorily account for everything that they know. Different frameworks tend to vary in the relative prominence that they give to the different aspects of our linguistic competence. Some of the frameworks that are most widely used have been developed as part of a theory of language in general, rather than simply as a framework for analyzing syntax. Their approaches to the analysis of syntax, therefore, reflect their overall orientation to the study of language. Transformational generative grammar, for example, which is best known, perhaps through the work of Chomsky, aims not only to describe and to explain language structure but also to investigate the nature of the mind (Quoted in Graddol et al, 1987). Systemic grammar, on the other hand, focuses more on the social aspect of language, aiming to account for the various linguistic choices that are available to us in different social situations. Within these broad general approaches, different frameworks have been developed that give more prominence to one aspect of syntactic structure than to others.

Within traditional linguistic theory, it was clearly understood that one of the qualities that all languages have in common is their creative aspect. Thus, an essential property of language is that it provides the means for expressing indefinitely many thoughts and for reaching appropriately in an indefinite range of new situations. The grammar of a particular language, then, is to be supplemented by a universal grammar that accommodates the creative aspect of language use and expresses the deep-seated regularities which, being universal, are omitted 
from the grammar itself. Therefore, it is quite proper for a grammar to discuss only exceptions and irregularities in any detail. It is only when supplemented by a universal grammar that the grammar of a language provides a full account of the speaker-hearer's competence (Graddol et al, 1987).

Reichenbach (1947) theorized about the tense of verbs. According to his theory of tense, there are at most three points in time which are relevant to the choice of tense in any given sentence: The point of speech (S); the point of the event (E); and The point of reference (R). This can be illustrated in the following utterance: Kwame had gone home. From this example, $S$ is the time when the statement was uttered, $E$ is the time when Kwame went home and $R$ is some definite time-point between $S$ and $R$ provided by the context. One of the main points of Reichenbach's theory is that he is able to distinguish the perfect tense from the simple past by assuming that in the former, $E$ and $R$ are different. Reichenbach's scheme works best for cases involving single, punctual actions; nonetheless, according to Dahl (1985), Reichenbach's accounts of the progressive in English and the aorist in Turkish are not convincing. That is partly due to the fact that the scheme basically only accounts for temporal reference and is not well suited for describing aspectual notions (ibid). However, there is at least one way in which the scheme can be made more powerful. Consider the following sentence: When I arrived, Kwame had tried to phone me twice during the preceding week. $R$ here must be the time when I arrived and $E$ the time point when Kwame tried to phone me. But it can be observed that there is nothing in Reichenbach's scheme that corresponds to the time referred to by during the preceding week. The function of that phrase could be said to specify a temporal frame for the $E$ point, that is, a time period within which they are located. Let us call the temporal frame $F$. In fact, although there are complex sentences like the above-where $S E R$ and $F$ are all distinct-they are rather infrequent and perhaps a little farfetched. It is quite common that we need to postulate an $F$ in order to give an adequate account of the interpretation of a sentence. There are, in fact, several ways in which a temporal frame can be determined. It may be introduced by an explicit time adverbial in the sentence. It may also have been introduced explicitly or implicitly in the earlier context, as in: I had a good time in Accra. I visited the central shopping mall twice (during the time I was in Accra).

\section{Review of Literature}

Many studies serve as channels to unveiling many different research findings on time, tense, and aspect in English grammar. Dahl (1985) was the outcome of a research project whose aim was to create a data-base containing comparable data on the tense, mood and aspect (TMA) systems of a large number of languages. The study was a contribution to the general theory of tense and aspect and of grammatical categories in general, based on the analysis made of data from more than 60 languages collected within the research project. The primary aim of this analysis was to test the hypothesis that the TMA categories that occurred in the languages of the world could be reduced to a small set of cross-linguistic category types. In contradistinction to the original project, in which the study was to cover the total TMA field, the final analysis was restricted to tense and aspect categories that occurred in affirmative declarative sentences.

Giorgi \& Pianesi (1997) considered the domain of the temporal and aspectual interpretation of sentences from a point of view of the interface between syntax and semantics. The empirical domain of investigation covered the Romance and Germanic languages with special reference to Italian and English. The study addressed questions concerning morphology and word order on the one hand, and questions concerning tense, aspect, and sequences of tense phenomena on the other. The researchers adopted the minimalist framework developed by Chomsky (1995). In particular, the authors proposed a theory to account for the cross-linguistic variation existing among Romance and Germanic languages in their temporal and aspectual systems. From theoretical and technical points of view, Giorgi \& Pianesi (1997) presented two leading ideas: The first aimed at providing an answer to the problem of morphological variation across languages. It was observed that the same tense was realized differently in the various languages. For instance, a particular tense could be realized with or without an auxiliary or the same tense might exhibit different constraints with respect to compatibility with temporal specifications. To explain these phenomena the authors developed the notion of hybrid categories which were typically found in some languages. The second idea concerned the interface with semantic interpretation. The authors proposed some interface conditions which might also have import for a sequence of tense theory.

Declerck, Reed and Capelle (2006) described the workings of the system of special verb forms used in English to locate situations in time. The goal of the authors was to write a grammar of the English tense system which was at the same time a scientific study and a work which could be used as a reference grammar by linguists and students of English with a basic knowledge of descriptive linguistics and a fairly advanced proficiency in English. Declerck et al (ibid) was meant to be a thorough study of the tense system based on a wealth of old and new observations and offering a coherent framework revealing the relations between the observations, accounting for them, and ultimately predicting most of them. The framework was a revised version of the descriptive theory presented in Declerck et al (ibid). Although it was presented without unnecessary formalization, it was a rigid framework which could easily be formalized and used in formal approaches like formal semantics or computational linguistics.

Harper and Charniak (1986) provided an interesting and revealing analysis of English tense and aspect 
involving relations between events. According to them, there are several kinds of events: the utterance event, which is associated with the time of the utterance; the main event or the event being described by the main verb of the sentence; the perfect event; and the progressive event. The representation of every sentence involves the utterance event and the main event; sentences with progressive or perfect aspect also involve progressive or perfect events. This treatment was quite different from Reichenbach's (1947) conception of reference time, which was assumed to be relevant to all sentences. To translate between the two systems, the reference time might be thought of as being represented by the perfect event in progressive sentences. In the case of perfect progressive, one might consider that there were two reference events, while in simple tenses there was no reference event at all. Alternatively, in a system like webber (1987) in which reference points for each sentence were used to construct an event structure, the tensed event was the relevant one.

From the literature, studies conducted on time, tense and aspect did not focus on the interrelationship between all the three grammatical concepts. For instance, Dahl (1985) was on tense and aspect in statements, Giorgi and Pianesi (1997) did an aspectual interpretation of the structure and meaning derivations in sentences, Declerck et al (2006) concentrated on time in relation to the verb and Harper and Charniak (1986) did an analysis of tense and aspect in English. What is yet to be known is the interpretation of the three grammatical concepts: time, tense and aspect in relation to communication. The current paper fills this knowledge gap.

\section{The Concept of Time}

Throughout the centuries people have developed various conceptions and theories about time and there are many similarities between them. From a certain perspective, however, they differ or complement each other. Given the extensiveness and diversity of these conceptions and theories, it is difficult to argue or even imagine that humans would have managed to develop a unified theory of time; however, language offers evidence that may be just the opposite of this assumption. Although in theory our perceptions of time may be very different and determined by geographical positions, era, philosophical schools and even religions, in languages different views come together to a relatively unified structure or image. Though it cannot be argued that the products are a universal notion, it is true however, that some elements can be found in numerous languages and that they have remained almost unchanged from ancient times to the present day.

The Greeks knew only the word chronos for both verbal tense and chronological time. The Italians today, for example, still speak of time (tempo) even when it comes to complex verbal structures where one could hardly claim they denote chronological time per se. In these cases, it is more about expressing relations between action and state within time relations (Graffi \& Scalise, 2002). The Slovenians also speak of time in general even though they distinguish between, for example, the present tense and the present time. The English are more precise and they use time for chronological time and tenses for verbal tense. We often speak of tense even when we mean aspect, aktionsart or mode (Zagar \& Grgic, 2011).

Time is a non-linguistic concept of when an action or a state is set in the present, past and future. Time is usually imagined as a straight line. On an arbitrary spot on the line is a point which marks the present time. To the left of the point, the past time is imagined, and to the right, the future time. The timeline is illustrated below:

The past The future

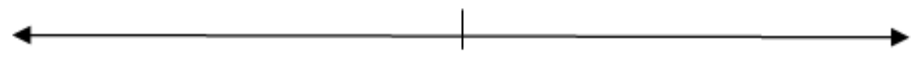

The Present

Smith (1991) defines time as being a single, unbounded dimension. Such a definition is in accordance with the straight line above. Despite the success that the above illustration has had among numerous researchers and educationists alike, it has been clear from ancient times that it is not sufficient for a graphical description of the complex time-tense problem. One of the principal reasons for this insufficiency is that the illustration lacks a definition of what the present, future and past are. One thing is, however, evident from this scheme; the present is a point which is arbitrarily placed on any given spot on a straight line. This point is thus a completely arbitrary notion. It follows then that the present is the first element of separation on the straight line and, until the present has been defined there is no past or future. The present is the point which separates and demarcates the past from the future, but on the other hand, it also binds and establishes them. The past begins somewhere in infinity and continues to the present, while the future begins with the present and continues to infinity. Naturally, the definition of time arising from the above mentioned arguments raises many questions and dilemmas.

A number of researchers have chosen to turn their attention toward understanding the concept of the present. Philosophers have not spoken about the linguistic or verbal present, but of extra-linguistic reality. Based on their own philosophical speculations, they have emphasized the present, or the past or the future, as the referential time. When Aristotle put forward the thesis of the nonexistence of the moment of the present (Binnick, 1991), this idea appeared for the first time in the history of western thought. The present, as such, does not exist. It does not have, if we resort to philosophical terminology, ontological value. Only through the demarcation of the past and the 
future is the link created which is referred to as the present. So this demarcation, which is the connecting link, is called the present (Zagar \& Grgic, 2011). The link is given purpose only through the existence of two time entities the past and the future. The Slovenian verbal system is based on the division into three time entities: the past, future and present. Even though there are systems that differ from Slovenian (and systems similar to Slovenian); for example, those which express time in the binary divisions of past/non-past or future/non-future, at the same time do not exclude the present as a notion. Regardless of how time is divided, therefore, human civilization cannot operate without a notion of the present within a system of time (Zagar \& Grgic, 2011).

The concept of time in relation to grammar has been discussed by numerous authors. By definition, it is a process through which time relations appear at a grammatical level and they influence grammatical structures, for example, syntax, morphology, word formation and so on. There are also processes of lexicalization of time. In this case, we are concerned with words which denote time or relations in time on the word formational level, but do not influence syntactic structures. For instance, the use of the word great-grandmother by no means obligates a speaker to use exclusively past tense, to change the word order in a sentence, nor to avoid certain adjectives where their use might seem internally inconsistent, as in a young great- grandmother.

In English, the grammatical taxonomies past and present do not necessarily correspond to time in the real world, but rather to grammatical features of the verbs. In English usage, events do not often fit neatly into categories of past, present and future time respectively. In fact, English employs a variety of structures to express different time references (DeCapua, 2008). In some situations, the relationship between time and grammatical form is often not succinct. For instance, a present form can be used to speak about a future event: The End-ofsemester examinations commence tomorrow. In this illustration, although the main verb commence is in the present tense form, the sentence has a futuristic reference. Similarly, past forms can also refer to present time. This might occur in a hypothetical conditional sentence: If I were the Vice-Chancellor, I would grant scholarships to all students. In spite of the fact that the verbs in the two clauses of the sentence are in the past, the sentence is not referring to past time. The verbs are in the hypothetical present which is identical with the ordinary past tense. The context of the sentence is unreal and the speaker might be day-dreaming. Certain forms in English may also refer to a different time than that expressed by their real names. For example, the present progressive aspect form may refer to either present or future time: "What are you doing?" "I'm washing." .While this interaction has a present time reference, the second "What are you doing on Saturday?" "I'm visiting my children" denotes future reference.

\section{Tense}

The term tense comes from Old French tens and from Latin tempus (both mean time). In grammar, tense is a category that locates a situation in time, to indicate when the situation takes place (Fabricius-Hansen, 2006). Tense is the grammatical expression of time reference, often using three basic categories of the past, the present and the future. In absolute tense, as in English, tense indicates when the time of assertion, time of completion or time of evaluation occurs relative to the utterance itself (time of utterance). In relative tense, on the other hand, tense is relative to some given event. Relative tense indicates temporal distance from a point of time established in the discourse that is not the present (i.e. reference to a point in the past or future). In languages which have tense, it is usually indicated by a verb or modal verb, often combined with categories such as aspect, mood, and voice.

Tense places temporal references along a conceptual timeline. This differs from aspect which encodes how a situation or action occurs in time. Typical tenses are present, past and future. Some languages only have grammatical expression of time through aspect; others have neither tense nor aspect. Some East Asian languages such as Chinese express time with temporal adverbs, but these are not required, and the verbs are not inflected for tense. In Slavic languages such as Russian, a verb may be inflected for both tense and aspect together. Aspect is often confused with the closely related concept of tense because they both convey information about time. If this distinction is not explicitly captured, communication may be affected. Aspect can be said to describe the texture of the time in which a situation occurs, such as a single point of time, a continuous range of time, a sequence of discrete points in time, whereas tense indicates its location in time. The most common aspectual distinction in languages of the world is that between perfective (complete, permanent, simple) and imperfective (incomplete, temporary, continuous). In many languages, grammatical forms combine tense and aspect and in many traditional approaches to grammar both are labeled tense.

An interesting example of the understanding of relations between chronological time and verbal tense is from Aristotle who wrote that there are three chronological times and thus three verbal tenses: The present, the past and the future (Quoted in Zagar \& Grgic, 2011). This statement was already refuted by other linguists during ancient times because Greek had six verbal tenses. The use of these tenses indicated complex relations between an extralinguistic and a linguistic reality. The number of tenses in a language may be disputed because the term tense is often construed to represent any combination of tense, aspect and even mood. In many texts the term tense may erroneously indicate qualities of uncertainty, frequency completion, duration or possibility.

As a linguistic concept, the term tense refers to the way verbs change their form in order to indicate at which time a situation occurs or an event takes place. Tense is a grammatical category which is marked by verb inflection 
and which is expressed when an event or action happens. Speaking strictly, only two English tenses are marked by the inflection of the verb: Present tense (talks) and past tense (talked). Leech and Svartvik (1975) define tense as the correspondence between the form of the verb and our concept of time (past, present or future). The two authors also postulate that English has two simple tenses: the present tense and the past tense. Tense entails inflectional changes in the lexical verb form to indicate distinctions in time. By adding the morpheme -ed to the verb talk, to form talked, it indicates that the event denoted by the verb occurred before the present time. The verb dress in the following sentences underwent inflections in order to mark both present and past tense. For example, Keren dresses decently (present tense); Keren dressed decently (past tense). However, in English, the expression of future time does not entail any inflection of the verb. Future time is expressed in a number of ways; one of them is a combination of the modal will and the lexical verb: The student will write an apology letter. Another expression of future time is done with the structure Be bound + to-infinitive. This is used to refer to future events which are certain or very likely to happen: Kojo is stuck in a traffic jam; therefore, he is bound to be late. In English, the present tense is used to refer to a present state which may extend indefinitely into the past and future: I am sick. The present tense is also used to denote habitual events: Sufficient rains make farmers happy. On the other hand, the past tense is used when the past happening is related to a definite time in the past: John was in the army for five years (He is out now).

Although tense is related to time, in certain instances, there is no correspondence between them. Thus, a present tense does not always refer to present time. Similarly, a past tense may not always refer to past time. For instance, in the sentence The bus leaves for Accra soon has a verb in the present tense leaves but it is referring to future time. In the same way, the sentence It's time you changed your apartment has a verb in the past tense changed which is not referring to past time. It is referring to an action that should have taken place long before now; it is long overdue.

The tenses in English: present tense and past tense can have simple forms as well as combinations with either the progressive or perfective aspect, or with both of them. The present and past tense forms of the verb jump can combine with other forms to generate complex verbal structures in the present and in the past. The verb phrases produced are aspectual in nature and they indicate complex structures that are composed of auxiliary verbs and main verbs:

I jump; I'm jumping; I have jumped; I have been jumping (Present)

I jumped; I was jumping; I had jumped; I had been jumping (Past)

\section{Aspect}

Grammarians of the Greek and Latin languages showed interest in aspect, but the concept did not enter into the modern western grammatical tradition until the $19^{\text {th }}$ century via the study of the grammar of the Slavic languages. The term aspect is a translation of the Greek word eidos meaning looking, look, form, figure, image, idea, notion and conception. The English word aspect is closer in meaning to quality, type, attribute and manner. Aspect meant two things in the $19^{\text {th }}$ century linguistics: It signified the distinction between perfective and imperfective verbs and also the meaning of a verb according to the phase of the action being expressed by the verb (Kortmannn, 1991). Meanwhile, German linguists used the term aktionsart for marking aspect. In contemporary times, there seems to be considerable terminological confusion among (especially English speaking) linguists where some authors use only the term aspect or aspectual while others combine the forms aspect and aktionsart. With the term aspect or aspectual, it is the distinction between perfective and imperfective verbs that is denoted. The term aktionsart denotes the type of verbal action.

In general, the division between aspect and tense is clearer than the division between aspect and aktionsart. Tense is known in most languages in one form or another. That is why the problem of a correct translation of the term tense, which marks a known notion in some languages, and an almost unknown one in others, does not appear as a central issue of discussion among the world's linguists (Zagar \& Grgic, 2011). Tense and aspect systems are complementary. They both express time relations and sometimes overlap. While tense denotes the time location of a certain action or state, aspect marks their internal (time) structure, or at least this is true in theory (Comrie, 1985). When used by speakers, however, the boundary between tense and aspect is more subtle. In some cases time location can be expressed with aspect, in others the internal time structure of the action can be expressed with the tense.

In linguistics, the term grammatical aspect refers to the possibility of using special grammatical forms (more specifically, verb forms) to express various meanings which have to do with how the speaker wants to represent the internal temporal structure of a situation (Declerck et al, 2006 ). From another perspective, aspect can be viewed as a grammatical category that expresses how an action, event or state, denoted by a verb, relates to the flow of time. Aspect concerns the manner in which a verbal action is experienced or regarded, for example as complete or in progress (Leech \& Svartvik, 1975). Semantically, aspects are different ways of viewing the internal constitution of an actualizing situation. These different ways are expressed by different markers on the verb.

Grammatical aspect is a formal property of a language, distinguished through over inflection, derivational 
affixes, or independent words that serve grammatically required markers of those aspects. Grammatical aspect is distinguished from lexical aspect or aktionsart, which is an inherent feature of verbs or verb phrases and is determined by the nature of the situation that the verb describes. The most fundamental aspectual distinction, represented in many languages, is between perfective aspect and imperfective aspect. Essentially, the perfective aspect looks at an event as a complete action, while the imperfective aspect views an event as the process of unfolding or a repeated or habitual event. English marks the continuous aspect with the verb to be coupled with present participle and the perfect with the verb to have coupled with past participle. For events of short durations in the past, the distinction often coincides with the distinction in the English language between the simple past $I$ plucked oranges this morning as compared to the progressive I was plucking oranges this morning. In describing longer time periods, English needs context to maintain the distinction between the habitual I played traditional music often in the past and perfective I have fixed my bicycle, although the construct used to marks both habitual aspect and past tense and can be used if the aspectual distinction otherwise is not clear.

Although English largely separates tense and aspect formally, its aspects do not correspond very closely to the distinction of perfective and imperfective that is found in most languages with aspect. Furthermore, the separation of tense and aspect in English is not maintained rigidly. Like tense, aspect is a way that verbs represent time. Tense and aspect relate the happening described by the verb to time in the past, present or future. However, rather than locating an event or state in time, the way tense does, aspect describes the internal temporal constituency of a situation, or in other words, aspect is a way of conceiving the flow of the process itself (Comrie, 1976). English aspectual distinctions in the past include: I sang, I used to sing, I was singing, I had sung, I had been singing; in the present tense I sing, I am singing, I have sung, I have been singing, I am going to sing; and with the future modal I will sing, I will be singing, I will have sung, I am going to sing. What distinguishes these aspects within each tense is not (necessarily) when the event occurs, but how the time in which it occurs is viewed: as complete, ongoing, consequentially planned and so forth. Certain aspectual distinctions express a relation in time between the event and the time of reference. This is the case with the perfect aspect, which indicates that an event occurred at a point in time, but has continuing relevance: I have danced, I had danced, I will have danced. English expresses some other aspectual distinctions with other constructions. Used to + verb is a past habitual, as in I used to plant flowers and going to + verb is a prospective, a future situation highlighting current intentions or expectation as in: I am going to go to the eye clinic tomorrow.

While many discussions of English grammar classify the present perfect as a past tense, it relates the action to the present time. This information about aspect is essential for effective communication in English. One cannot say of someone now deceased that he has talked or has been talking. The present auxiliary implies that he is in some way present (alive), even if the action denoted is completed (perfect) or partially completed (progressive perfect). Aspects can also be marked on non-finite forms of the verb: (to) be crying (infinitive with progressive aspect), (to) have cried (infinitive with perfect aspect), having cried (present participle or gerund with perfect aspect), and so on. The perfect infinitive can further be governed by modal verbs to express various meanings, mostly combining modality with past reference: I should have cried. In particular, the modals will and shall and their subjunctives would and should are used to combine future or hypothetical reference with aspectual meaning.

\section{Conclusion}

It is certainly true that the ways in which people perceive time are grounded in a physical sensation of chronological time. The way time is expressed is a result of the conceptualization of time relations. Although time is regarded as an extra-linguistic category, and that it exists independently of language, it is an integral part of tense and aspect since the latter concepts convey information about time. In English, the concept of time is viewed in relation to tense and aspect. Tense is a linguistic concept: It denotes the form taken by the verb to locate the situation referred to in time. Aspect refers to how an event or action is to be viewed with respect to time, rather than to its actual location in time. Aspect expresses a feature of the action related to time, such as completion or duration. Language injects the concept of time into processes which do not in and of themselves posses it. Time is a notion which helps humans to organize their understanding of how things happen in the world and helps us to conceive such happenings. Grammar plays an important role in the language used in communication. The information provided in this paper on time, tense and aspect contributes to effective communication in English.

\section{REFERENCES}

Binnick, I. R. (1991). Time and the Verb: A Guide to Tense and Aspect. New York: Oxford University Press pp. 135-6.

Chomsky, N. (1965). Aspects of the Theory of Syntax. USA: Massachusetts Institute of Technology.

Chomsky, N. (1995). The Minimalist Program. MIT Press, Cambridge, Mass.

Comrie, B. (1985). Tense. Cambridge: Cambridge University Press.

Comrie, B. (1976). Aspect. Cambridge: Cambridge University Press.

Dahl, O. (1985). Tense and Aspect Systems. UK: Basil Blackwell Ltd. 
DeCapua, A. (2008). Time, Tense and Aspect of verbs. In: DeCapua, A. (ed.) Grammar for Teachers. Springer, Boston, MA, pp 165-209.

Declerck, R. ,Reed, S. \& Capelle, B. (2006). The Grammar of the English Tense System: A Comprehensive Analysis. Berlin: Walter de Gruyter GmbH \& Co. KG.

Fabricius-Hansen. (2006). Tense. The Encyclopedia of Language and Linguistics. $2^{\text {nd }}$ ed.

Fairclough, N. (1992). Discourse and Social Change. Cambridge: Polity Press.

Giorgi, A. \& Pianesi, F. (1997). Tense and Aspect: From Semantics to Morphosyntax. New York: Oxford University Press.

Graddol, D., Cheshire, J. \& Swarm, J. (1987). Describing Language. Buckingham: Open University Press.

Graffi, G. \& Scalise, S. (2002). Le Lingue e il linguaggio. Introduzione alla linguistic. Bologna: II Mulino.

Harper, M. P. \& Charniak, E. (1986). "Time and Tense in English". Proceedings of the ACL Conference, Columbia University, New York.

Krech, D., Crutchfield, R. S., \& Ballachery, E. L. (1962). Individual in Society: A Textbook of Social Psychology. New York, McGraw-Hill.

Kortmannn, B. (1991). "The Triad 'tense-Aspect-Aktionsart' Problems and Possible Solutions: Perspectives on Aspect and Aktionsart". Belgium Journal of Linguistics 6.

Lakoff, G. \& Johnson, M. (1980). Metaphors we live by. Chicago: University of Chicago Press.

Leech, G. \& Svartvik, J. (1975). A Communicative Grammar of English. UK: Longman Group Ltd.

Reichenbach, H. (1947). Elements of Symbolic Logic. New York: Macmillan.

Sapir, E. (1921). Language: An Introduction to the study of speech. New York: Harcourt, Brace and Company.

Sirbu, A. (2015). "The Significance of Language as a tool of Communication." Miceacel Batran Naval Academy, Bulletin, Volume XVIII, Issue 2, 405-406.

Smith, S. C. (1991). The Parameter of Aspect. Dordrecht: Klumer Academic Publisher.

Webber, B. (1987). "The Interpretation of Tenses in Discourse." Proceedings of the ACL Conference, Stanford university California.

Zagar, Z. I., \& Grgic, M. (2011). How to do Things with Tense and Aspect: Performativity before Austin. UK: Cambridge Scholars Publishing. 